\title{
Professional competencies as a component of professional training of a fitness trainer-teacher in higher education institutions
}

Oksana Kornosenko1 Pavlo Khomenko ${ }^{2}$ Iryna Taranenko ${ }^{3}$ Valeriy Zhamardiy ${ }^{4}$ Olena Shkola ${ }^{5}$ Hanna Tolchieva ${ }^{6}$ Volodymyr Saienko ${ }^{7}$ Nataliya Batieieva ${ }^{8}$ Petro Kyzim9

\section{Journal for Educators, Teachers and Trainers, Vol. 12 (1) https://jett.labosfor.com/}

Date of reception: 27 April 2020

Date of revision: 25 July 2020

Date of acceptance: 23 September 2020

Oksana Kornosenko, Pavlo Khomenko, Iryna Taranenko, Valeriy Zhamardiy, Olena Shkola, Hanna Tolchieva, Volodymyr Saienko, Nataliya Batieieva, Petro Kyzim (2021). Professional competencies as a component of professional training of a fitness trainer-teacher in higher education institutions.Journal for Educators, Teachers and Trainers, Vol. 12(1). 67 - 71.

${ }^{1}$ Doctor of Pedagogical Sciences, Associate Professor, Associate Professor of the Department of Theory and Methodology of Physical Education, Adaptive and Mass Physical Culture, Poltava V. G. Korolenko National Pedagogical University, Poltava, Ukraine.

${ }^{2}$ Doctor of Pedagogical Sciences, Professor of the Department of Medico-Biological Disciplines and Physical Education, Poltava V. G. Korolenko National Pedagogical University, Poltava, Ukraine.

3 Ph.D. in Pedagogics, Lecturer of the Department of Theoretical and Methodological Foundamentals of Teaching Sports Disciplines, Poltava V. G. Korolenko National Pedagogical University, Poltava, Ukraine.

${ }^{4}$ Ph.D. in Pedagogics, Associate Professor of the Department of Physical Education and Health, Physical Therapy, Ergotherapy with Sports Medicine and Physical Rehabilitation, Ukrainian Medical Stomatological Academy, Poltava, Ukraine.

5 Ph.D. in Pedagogics, Associate Professor, Head of the Department of Physical Education, Municipal Establishment «Kharkiv Humanitarian Pedagogical Academy» of Kharkiv Regional Council,

Kharkiv, Ukraine.

${ }^{6}$ Ph.D. in Pedagogics, Associate Professor of the Department of Olympic and Professional Sports, Luhansk Taras Shevchenko National University, Starobilsk, Ukraine.

${ }^{7}$ DSc. in organization and management, Professor of the Academy of Management and Administration of the Faculty of Economics and Pedagogical, Opole, Poland.

${ }^{8} \mathrm{PhD}$ in Physical Education and Sport, Associate Professor of the Department of Choreographic Art, Kiev National University of Culture and Arts, Kyiv, Ukraine.

${ }^{9}$ Associate Professor, Associate Professor of the Department of Gymnastics, Dance Sports and Choreography, Kharkov State Academy of Physical Culture, Kharkiv, Ukraine 


\title{
Journal for Educators, Teachers and Trainers, Vol. 12 (1) \\ ISSN 1989 - 9572 \\ https://jett.labosfor.com/
}

\section{Professional competencies as a component of professional training of a fitness trainer-teacher in higher education institutions}

\section{Oksana Kornosenko ${ }^{1}$, Pavlo Khomenko ${ }^{2}$, Iryna Taranenko ${ }^{3}$, Valeriy Zhamardiy ${ }^{4}$, Olena Shkola ${ }^{5}$, Hanna} Tolchieva $^{6}$, Volodymyr Saienko ${ }^{7}$, Nataliya Batieieva ${ }^{8}$, Petro Kyzim ${ }^{9}$

${ }^{1}$ Doctor of Pedagogical Sciences, Associate Professor, Associate Professor of the Department of Theory and Methodology of Physical Education, Adaptive and Mass Physical Culture, Poltava V. G. Korolenko National Pedagogical University, Poltava, Ukraine.

${ }^{2}$ Doctor of Pedagogical Sciences, Professor of the Department of Medico-Biological Disciplines and Physical Education, Poltava V. G. Korolenko National Pedagogical University, Poltava, Ukraine.

${ }^{3}$ Ph.D. in Pedagogics, Lecturer of the Department of Theoretical and Methodological Foundamentals of Teaching Sports Disciplines, Poltava V. G. Korolenko National Pedagogical University, Poltava, Ukraine.

${ }^{4}$ Ph.D. in Pedagogics, Associate Professor of the Department of Physical Education and Health, Physical Therapy, Ergotherapy with Sports Medicine and Physical Rehabilitation, Ukrainian Medical Stomatological Academy, Poltava, Ukraine.

${ }_{5}$ Ph.D. in Pedagogics, Associate Professor, Head of the Department of Physical Education, Municipal Establishment «Kharkiv Humanitarian Pedagogical Academy» of Kharkiv Regional Council,

Kharkiv, Ukraine.

${ }^{6}$ Ph.D. in Pedagogics, Associate Professor of the Department of Olympic and Professional Sports, Luhansk Taras Shevchenko National University, Starobilsk, Ukraine.

${ }^{7}$ DSc. in organization and management, Professor of the Academy of Management and Administration of the Faculty of Economics and Pedagogical, Opole, Poland.

${ }^{8} \mathrm{PhD}$ in Physical Education and Sport, Associate Professor of the Department of Choreographic Art, Kiev National University of Culture and Arts, Kyiv, Ukraine.

${ }^{9}$ Associate Professor, Associate Professor of the Department of Gymnastics, Dance Sports and Choreography, Kharkov State Academy of Physical Culture, Kharkiv, Ukraine

Email ID: kornosenko@ukr.net, homenko1402@ukr.net, irinavad.tar.ko@gmail.com, Shamardi@ukr.net, alesikk1974@gmail.com, asergeeva29@gmail.com, saienko22@gmail.com, kyzim@i.ua, petrkyzim@i.ua

\begin{abstract}
The article presents professional competencies as an important component in the professional training of future trainers-teachers of fitness in higher education institutions. The purpose of the work is to substantiate professional competencies in the professional training of future trainers-teachers in fitness in higher education institutions. The effectiveness of the use of professional competencies in professional activities is ensured by a combination of medical-biological, social-humanitarian and psychological knowledge from sports and pedagogical disciplines. The learning process is based on integrative interdisciplinary links, unity and interconnection of sports and professional and pedagogical improvement of physical and mental abilities with the use of modern information and communication technologies, cooperation of teachers and fitness trainers, development of international relations and cooperation. The use of modern educational technologies, special computer programs in combination with traditional forms of professional training provides an opportunity to increase the effectiveness of training. In the case of the use of such training in the formation of professional competencies, almost all students are involved in cognitive activities, constant exchange of knowledge. At the same time, information and communication technologies almost naturally combine methods and means of learning and data processing. In order for graduates to become highly qualified and competent professionals, they need not only to acquire a certain set of knowledge and skills, but also to gain sufficient experience in modern information technology, and most importantly, to acquire the ability to self-development, improving their professional competencies.
\end{abstract}

Keywords: higher education institutions, professional competencies, fitness trainer-teacher, professional training. 


\section{INTRODUCTION}

Today the basic organizational link of athletic-health-improving activity of different age people is the fitness club. The motive force of the fitness sphere is the people's need in the permanent organized motive activity, in developing and supporting the physical characteristics at the level, which is necessary for a fully functioning person. The efficiency of modern fitness technologies directly depends on the work of fitness coach - a competent specialist in the sphere of physical education and person's health, able to organize and embody group and individual fitness programmes. Conscious aspiration for the maintenance and strengthening of health, awareness of advantages of lessons with coach above the independent training, scientists examine as an index of the high level of general and physical culture, consider fitness sanitation as the perspective direction of athletic activity.

Modern fitness is the direction of athletic-health activity, which has the sporting or conditional-development orientation, based on using the complex of different physical exercises (aerobic, power, dance, martial arts, elements of health gymnastics, psych training, etc.) that are conducted in different conditions (in a pool, reservoir, outside playground, gym, at home), with the different age-related contingent and provide the optimal moving mode, physical preparedness, strengthening of health. Accordingly, a fitness coach is a competent specialist in the area of human health and physical education, who must solve professionally the problems of health improvement, optimization of the moving mode, an increase of formation level of physical qualities for the people of different age, and also the state of health with the help of health fitness facilities.

In particular, scientist (Nash, 2018) investigates the training organized by the system of Cross-Fit. The author considers Cross-Fit as one of the most popular directions of training activity in the world, and coaches of CrossFit as the leading specialists in the development and popularization of this fitness technology. M. Nash proves that qualified fitness coaches see correlated connections between concepts of «health» and «fitness» through the prism of gender differences. Scientists (Rustaden et al., 2017) offer the technology of application Body Pump training as an alternative to the traditional training with the large loading for overweight and obesity women. Researchers proved that this programme helps to promote metabolism and can be the same effect as well as traditional power training.

While scientists (Tolle et al., 2018) examine the needs of people, who have spinal cord injuries, offer the conception of fitness gyms network, specially intended for people with different neurological disorders. The conception consists in the integration of professional activity of specialists, who have work experience with people with special needs and patient rehabilitation, and also the introduction of standardized measures of verification and estimation after the functional state and quality of life of such persons. The research was conducted with the purpose to single out the effective approaches of fitness centres and health institutions to the rehabilitation of people with spinal cord injuries, who require the application of special trainer equipment and the help of qualified personnel.

The work content of scientists (Rapkiewicz et al., 2018) consists in the comparison of influence results of fitness programme by the system of Muay Thai, which was conducted with women of different preparedness level in twice- and three times a week mode. Summarizing results, researchers prove the effectiveness and identical degree of adaptation possibility of both double and triple application of Muay Thai fitness training. There are works (Zhamardiy et al., 2020) to substantiate the scientific foundations of the system of professional education of fitness coaches' and recommendations for conducting fitness classes with students. In the study (Butenko et al., 2017), it is recommended that individual fitness exercises be performed in an open area during health tourism.

So, scientists of (Zhurat et al., 2019) examine the formation of foreign professionally-oriented competence through modelling in the educational process of typical situations of real professional communication. They insist that students' communicative activity in professionally-oriented communication in a foreign language is the system, which consists of organizational-motivational, informational-procedural and criteria-based and effective elements following from the social nature of the human activity. The model of the educational system provides for such components as maintenance of educational material, ways and methods of teaching, the supply of personal value of educational material, establishment of subject-object relations, psychological and pedagogical methods of stimulation, etc.

Scientists (Vanchukhina et al., 2019) worked out the model of administrative education in technical universities, that is based on interdisciplinarity and adaptivity of educational technologies, beginning with the basic level of education (Bachelor's Degree) ending with the competence in an area of technique and economics. The system of professional education modelled in theory integrates two components - engineering and economical, and also includes modern teaching technologies. Scientists (Oluwajana et al., 2019) examine the possibility of formation of hedonic motivation through the use of gaming educational environment. For this purpose, the model of Hedonic - Motivation System Adoption in Gamified Learning Environment in the educational process was worked out and implemented. 
The relevance of the study is due to the fact that in developing countries there has been a steady deterioration in the health of the population and, in particular, student youth. Therefore, in the conditions of qualitative development of the younger generation, it is necessary to find the most effective ways to improve the educational process in physical education. Physical education can only give the expected results when it is carried out according to a certain model, with the right choice of methods, tools and forms of organization of educational and extracurricular processes that accurately meet the goals and objectives of society in this area. Therefore, the object of our research is future fitness coaches' professional training in higher educational institutions.

\section{MATERIALS AND METHODS}

The aim of the study is to ground conceptual principles of future fitness coaches' professional training in higher educational institutions; to consider and adopt the components of the system, personal, activity, competence, integrational-differentiative scientific approaches to the specificity of fitness coaches' professional training; to develop the model of the system of fitness coaches' professional training and to ground the pedagogical conditions which provide its efficiency.

The pedagogical experiment was carried out on the basis on Poltava National Pedagogical University named after V. G. Korolenko (Ukraine), which was attended by twelve study groups of students (a total of 294 people, including 161 - boys and 133 - girls) from historical, natural, psychological-pedagogical, physicalmathematical and philological faculties. All students were divided into control and experimental groups by the method of even distribution of groups. General scientific and special research methods were used to achieve the set goal and solve the problems, interconnected and consistently applied throughout the study: theoretical (for the formation of theoretical and methodological foundations of the study): analysis and generalization of philosophical, sociological, psychological, pedagogical, valeological literature; study of educational programs; regulatory and legislative documents; methodical recommendations and textbooks on psychological and pedagogical disciplines; study of the experience of physical education departments in higher education institutions; empirical (to determine the general health of students): methods of collecting information (questionnaires, surveys, pedagogical testing and observation of students' educational and training activities), analysis of learning outcomes, interviews, methods of expert assessments, self-assessment, generalization of independent characteristics; experimental (for the analysis of the basic ways of research of complex indicators): ascertaining, formative, control stages of pedagogical experiment, visual aids; statistical (to assess the statistical significance of differences in the status and dynamics of changes in health indices): descriptive statistics, determination of statistical significance of differences between groups by the student's method and correlation analysis by the Pearson method.

\section{RESULTS AND DISCUSSION}

The conception is based on scientific points of philosophy of education, pedagogical theory and practice, mechanisms and principles of physical culture and sport, indicates the content and basic directions of development of the system of future fitness coaches' professional training in higher educational institutions and contains three interrelated concepts that assist the realization of the leading idea: methodological (shows the intercommunication and interaction of scientific approaches (system, individual, activity, competence, integrational-differentiative) to the modelling of future fitness coaches' professional training system as an innovative organized, purposeful, dynamic process, that needs the development and introduction of the educational-technological and methodological provision and determination of the complex of its effective functioning pedagogical conditions; theoretical (determines the fundamental theories, conceptions, ideas and definitions that are the base of pedagogical process essence understanding in higher educational institutions, problems of future fitness coaches' professional training, a specificity of its aims and tasks, functions of fitness coaches' professional activity; allows to investigate interrelated structural components and elements of the model of the system of future fitness coaches' professional training in higher educational institutions); technological (provides the development, introduction and experimental verification of the system of future fitness coaches' professional training, its educational-technological provision and realization methodology in the pedagogical process).

By results of the analysis of modern philosophical and psychoeducational conceptions, the application features of methodological approaches in future fitness coaches' professional training are discovered and grounded. System approach provides the unity of training elements as a dynamic system to the structure of which belong: aim, tasks, methodological approaches, principles, subject training, the interaction of teachers and students, methods, facilities, forms, stages of training, which are orientated on the result and provide functioning and integrity of the system. A personal approach is oriented at personality comprehensive development, the formation of individual style of fitness coaches' professional activity taking into account abilities, state of health, needs and wishes of the student. In the context of activity approach, future fitness coaches' professional training 
is considered through the prism of varieties of coach's activities, that predetermines the priority use of active methods and modern educational-technical facilities in the process of professional education, application of which lead to the mastering of new knowledge, abilities and skills, represent general mechanisms of students' mastering of social and coach's experience taking into account individual characteristics, intensify the development of personal qualities, cognitive and motive abilities. Competence approach is considered as the educational process orientation on the formation of professional competence, which is determined in the combination of professional knowledge, abilities and skills that reflect theoretical, practical and methodological readiness and capacity for its creative realization in different social situations of practical professional activity; emphasizing the personal qualities, mental and ethical and cultural values, yearning for physical perfection and motive experience transfer, self-development and self-education during life. The integrational-differentiative approach is realized as complex scientific mean, which is based on the combination of integration and differentiation principles of general, professional and special professional disciplines content with the aim of optimal conditions provision for the creative and productive formation of professional competence, assistance to self-development of future fitness coach's personality in higher educational institutions.

The model of the system of future fitness coaches' professional training is viewed as description and theoretical ground of structural components (conceptual, intensive, technological, effective), their elements (aim, the interaction of lecturers and students, stages of professional training, methods and forms of teaching, educationaltechnological and methodological provision, means of monitoring of professional competence formation, subject training (integration and differentiation of disciplines of different training cycles), that provide the formation of professional medical-biological, social-humanitarian, psychoeducational knowledge, professionalmotive abilities and skills peculiar to fitness coach) and intercommunications between them within the limits of the integral pedagogical process.

Every component of the model of the system has its purposeful orientation, forecast results, hierarchical subordination in the general structure, clear sequence. The central elements of the model's conceptual block are the aim as the foresight of desirable (ideal) result, methodological approaches and principles. The generalized aim of future fitness coaches' professional training is the formation of professional competence taking into account the theory and practice of health-improving fitness, functions of fitness coach's professional activity, modern scientific acquisitions in the sphere of physical culture and humans' health, creation of individual style of professional activity and guidance, self-perfection skills assignment and professional outlook broadening.

Contensive block of the model is characterized by the professional competence of future fitness coaches through the specification of necessary for implementation professional functions of knowledge, abilities and skills and is realized in subject training. The study of general disciplines creates the understanding about the coach's professional functions, forms the interest in coach's activity, the system of motivational options and professional values, perfects the standards of speech and communication, etc. Professional disciplines allow planning, to organize and to forecast training results in general. Special professional disciplines allow forming professional knowledge, abilities, skills and qualities, necessary for direct fulfilment of professional functions, which are the realization of the group and individual training, development of individual programmes, consultations, etc. Formation of a difficult hierarchical structure of connections between separate courses provides the transformation of general and professional background and abilities in special professional. General, professional and special professional disciplines are realized in educational (implementation of in-class and individual tasks, pedagogical practices, participation in athletic-recreational events), upbringing (participation in educational events of professional-practical direction) and research (preparation of educational-scientific works, participation in conferences, methodological seminars, round tables, training, contests) activity, that assists the formation of the system of necessary knowledge, abilities, skills, increase of intellectual potential, development of professional thinking, capacity for research work.

Technological block of the model of the system predetermines a stage-by-stage mastering by future fitness coaches the maintenance of professional competence using the tool-technological provision of the training process, a realization of interrelated methods, facilities and forms of teaching. The optimal forms of educational process organization for future fitness coaches are discovered: general (in-class work - lectures, practical lessons, seminars, practices, control events, etc.); specific types of forms (independent, frontal, group, collective-group, individual-group, work in the pairs of variable configuration, etc.). Methods which meet the requirements of fitness coaches' professional training specificity are detected (reproductive, active, methods of physical education). The means of fitness coaches' training are singled out: pedagogical (textbooks, methodological recommendations, dictionaries, video- and photographic materials, presentations, educationaltechnical devices (trainers), online computer tutorials, sporting inventory and equipment, etc.) and specific physical exercises. Monitoring of formation of both separate components and professional competence, on the whole, is provided by transparent ways of controls (control works in written form, oral answers, testing of theoretical-methodological preparedness level, evaluation of anterolateral steps fulfilment, a realization of fitness training, diagnostics of physical development and functional state, etc.). 
Effective block of model of the system provides the realization of the pedagogical evaluation of future fitness coaches' professional competence components formation on criteria and indexes (motivational-evaluative with indexes: cognitive interest in fitness coach's activity; realization of its public consequence, firm motivation to education and profession acquisition; health-keeping with indexes: firm outlook position and behaviour in relation to conscious and careful attitude toward the health of people, physical and psychological state; medicalbiological knowledge, necessary for person's health-keeping during fitness trainings, traumatism prevention; professional-gnoseological with indexes: health-improving fitness knowledge (structure and types of lessons, fulfilment techniques and methodology of different types of fitness exercises teaching and typical errors during fulfilment); capacity for self-education and professional self-improvement; operational-activity with indexes: ability to coordinate movements with music, to do basic exercises of classic and step aerobics, power exercises which have acquired the level of motor skill; to develop, to demonstrate and to teach exercise complexes and dancing compositions of cardio- and power orientation, to conduct aerobic (fitball aerobics, step aerobics, dance aerobics, etc.), mental (pilates, stretching, etc.), power (Body Pump, CrossFit, etc.) programmes for people of different age and level of training, taking into account their state of health, needs and wishes; presence of own functional and physical readiness sufficient level; control-prognostic with indexes: knowledge of diagnostics methods and tools for determination of training efficiency, evaluation of the organism's systems state during exercise; ability to apply monitoring results for correction and improvement of training process; informationcommunicative with indexes: ability to work with computer software and equipment for health status diagnostics, functional indexes and physical qualities; ability to apply verbal and non-verbal means of communication and terminology while training, to control voice while giving instructions and orders; creative-searching with indexes: aspiration to creative self-realization and need of individual self-expression; ability for professional reflection; application of innovative pedagogical and fitness technologies; research activity in projects making of group lessons and programmes of individual development and their practical realization; formation of individual creative style of professional activity and guidance). These denoted criteria and indexes made possible the differentiation of professional competence of fitness coaches after qualitative levels (elementary, reproductive, heuristic, creative).

Elementary level is characterized by a weak personal interest of fitness coach's activity, shortage of cognitive reasons, the unformed system of professional values; denoted by the complication in planning and programme development of person's progress, in the complete use of fitness programmes health resources; is the simple recognition and reflection of separate facts and theories, absence of systematization of mastered educational material and its practical application in professional activity; the poorly developed feeling of musical tempo, defects in basic exercises performance, use of kyuing techniques, shortage of physical preparedness; insufficiency of methodologies possession of person's health status evaluation, abilities to apply monitoring results for correction and improvement of the training process, so all these characteristics show the low level of control-prognostic criterion indexes formation; the elementary abilities can be seen as to work with computer programs, blanks in communication skills development, lack of ability correctly to apply verbal and non-verbal means of communication and terminology while training, insufficient voice control while giving instructions and orders; finds out unreadiness to creative self-realization, individual self-expression and professional reflexion.

Reproductive level is characterized by realization of specificity, functions and public meaningfulness of fitness coach's profession, but weak motivation to professional training and activity; the understanding of necessity of health strengthening and maintenance, but there is a lack of medico-biologic knowledge for person's healthkeeping while fitness trainings, traumatism prevention; fragmentariness of knowledge, ability to reproduce theoretical material of different disciplines on reproductive level; the understanding of exercises combinations construction methods, ability to reproduce them under the set standards, difficulties in development of own compositions and lessons in general; the separate methodologies possession of evaluation of organism's functional state and dynamics of physical development, however there are difficulties in prognostication and rectification in training planning, relying on the results of diagnostics and control results; distinguished the imperfection of abilities to plan, to carry out and to analyze training process with the help of software tools and computer technologies, difficulties in use of kyuing techniques, establishment of contacts and interpersonal communication; creative-searching criterion is characterized by difficulties in application of innovative fitness technologies and group and individual programmes development which need the high degree of creativity.

Heuristic level discovers the purposefulness and firmness of reasons, realization of ways and methods of career development in future professional activity; the firm outlook position in relation to conscious and careful attitude toward health, own physical and psychological state; available level of medical-biological knowledge allows to create optimal conditions for health-keeping trainings, to organize training and to standardize physical load; distinguished the capacity for general orientation in application of basic theoretical positions, abilities to compare, to summarize, to systematize information, independently to apply it in practice while solving professional tasks, to explain the used facilities and technologies; the indexes of operational-activity criterion certify the perfect possession of basic exercises techniques, sense of tempo and rhythm, ability to develop 
simple connections and compositions, certain complication in group guidance; the possession of evaluation methodologies of health's state and physical development's dynamics and, at the same time, lack of experience while results' monitoring application for training process correction; distinguished the ability to use necessary computer programs, however, insufficient voice control while giving instructions and orders; creative-searching criterion characterizes the ability to estimate and correct own activity, aspiration for creative self-realization and need in individual self-expression, appearance of individual characteristics and creative approach in professional activity.

Creative level is characterized by formation of cognitive motives and system of values, positive relation and high effectiveness of professional training; marked as possession of methodologies and facilities of maintenance and strengthening of health, ability to complete scientifically reasonably and methodologically correct the maintenance of training programmes with health-keeping components; the formed abilities to use innovative fitness technologies, to develop the projects of group and individual programmes, to implement them in practice, the expressiveness of individual creative style of professional activity and guidance can be mentioned. The improvement of the system of future fitness coaches' professional training according to the developed conception needs motivation and provision of complex of pedagogical conditions, which are aimed to the optimization of pedagogical process of this profile specialists' professional competence formation following the actual social needs and requirements of athletic-health institutions.

The first pedagogical condition consists in the integration of medico-biologic, social-humanitarian, psychoeducational knowledge in disciplines of different cycles of training based on integrative interdisciplinary connections in one integral systematized process of fitness coaches' professional competence formation and is connected with the necessity of general, professional and special professional disciplines maintenance interpenetration. Provision of this condition leads to expansion and specification of professional information, an increase of its professional direction, the interconnection of theory and practice, readiness to use it in professional situations, ability to form the well-defined system of separate educational themes and disciplines scientific knowledge, to have students' great progress while doing tasks and projects related to practical professional activity, to see a general increase of students' erudition.

The second pedagogical condition is the unity and interconnection of sport and professional-pedagogical perfection of professional-motive abilities and skills formation, it is based on programming and algorithmization of education which consists in process control of mastering of motive abilities and skills and proper control after them with the observance of exact phases and sequence of operations: the creation of the concept of new motion concept. Realization of this condition improves the quality of mastering sport and professional-pedagogical abilities and skills, provides the increase of the general level of professional competence.

The third pedagogical condition provides the application of innovative of information-communicative technologies and educational-technical facilities in the process of fitness coaches' training (presentations, videoand photographic materials, online-services, online computer tutorial «Health Promotion Fitness», Stepper trainer simulator). The online computer tutorial «Health Promotion Fitness» contains the theoretical, methodological and practical modules that allow mastering the knowledge of organization and methodology of realization of the health promotion fitness trainings. Stepper trainer simulator (STS) is the educational-technical device constructed with the aim of perfection of future fitness coaches' professional training process, consisting of the computer control program, electronic device and floor platform (dancing board). Realization of this condition in pedagogical training process substantially promotes the level of formed professional-gnoseological, information-communicative and operational-activity components of fitness coaches' professional competence.

The fourth pedagogical condition is the combined teaching of the special professional disciplines on principles of a collaboration of higher educational institutions lecturers and practising fitness coaches, for students' «deepening» in a direct professional environment. It is discovered that the involvement of professional fitness coaches to students' training is appropriate in different pedagogical activity directions: educational, upbringing, research. It is also appropriate to invite fitness coaches on educational athletic-health events: fitness marathons, competitions, contests, sent to the popularization of a healthy way of life. It is distinguished that of great practical value for students is information, which practising fitness coaches give in reports during research and practical conferences and methodological seminars. Implementation of this condition promotes students' motivation to education, forms an idea about the prospects of further professional development (career advancement), aspiration to have a high level of professional competence.

The fifth pedagogical condition is characterized with the development of international connections and collaboration in the context of integration to the world and European educational environment, realization of Bologna declaration theses and includes: realization of joint scientific events, collective writing of scientific works, reviewing of scientific researches; exchange of scientific information and innovative educational methodologies and practices in the sphere of physical culture and sport; exchange of delegations, the invitation of scientists and teachers from different countries for realization of collective researches and studies, scientific and educational projects, teaching; international academic mobility of scientific-pedagogical members; writing and edition of textbooks, monographs, educational-methodological manuals and publication of scientific 
materials in foreign publishing houses, participation in the international book exchange. Realization of this condition assists deepening of skills of cross-cultural communication, the perfection of foreign languages possession, enriching of educational, scientific, sports experience, mind-broadening; academic mobility allows getting knowledge in the spheres of science and European and world culture, exchange of experience, mutual recognition of achievements and qualifications in educational and scientific institutions.

The effectiveness of the proposed model of professional training of future fitness coaches' professional training was evaluated by the results of control tests. At the beginning of the academic year (September), the level of the special physical condition of future fitness coaches' professional training in control and experimental groups was assessed. Control tests were conducted at the end of the academic year (May-June). Students who dropped out of the experimental and control groups during their studies were not included in the statistical processing and were not replaced by others. Analysis of the last publications of scientists showed us that their ideas about the questions of modelling of the system of specialists' professional training had not identified the clear grounding of the system of fitness coaches' training. Analytical aspects of specialists' training of different profiles and specialities are observed in some scientific researches, but they do not relate to fitness coaches' training, that motivated us to the fulfilment of this research.

At the same time, insufficient attention in scientific investigations is given to the complex examination of the system of future fitness coaches' professional training, exposure of mechanisms and specificity of the professional activity of these specialists of different types, finding out the component content of their professional competence based on their functions fulfilment generalization, and also pedagogical conditions, principles and models of fitness coaches' professional training in higher educational institutions, forms of educational activity organization, methods and facilities of education that suppress the increase of this speciality experts' training quality.

\section{CONCLUSION}

The system of future fitness coaches' professional training in higher educational institutions is in theory grounded and worked out. The model of the system contains four correlated components: conceptual, intensive, technological and effective. The central components of a conceptual block are aimed at prevision of the ideal result of all training system, methodological approaches and principles. The intensive block of model is characterized by the future fitness coaches' professional competence through the specification of necessary for implementation professional functions of knowledge, abilities and skills and is realized in subject training based on integrated interdisciplinary connections and differentiation of the professionally adapted fitness coaches' training maintenance. Technological block of the model predetermines the stages of future fitness coaches' training as the gradual realization of interrelated methods, forms and facilities of teaching which provide structural integrity of the pedagogical process. Stage-by-stage monitoring of professional competence indexes formation is ensured by transparent ways of controls. Effective block of model is sent to the realization of pedagogical evaluation of future coaches' professional competence formation on reasonable criteria and indexes and its quality differentiation after levels (elementary, reproductive, heuristic, creative).

To perspective further work tendencies belong modelling of future fitness coaches' professional training in conditions of blended learning; development and introduction of multimedia manuals for future fitness coaches' professional training quality provision; preparation of the programme-normative and educationalmethodological provision for advanced training of physical culture teachers with the use of the modern fitness programmes in professional activity; development of pedagogical technology of physical culture teachers' retraining to activity in the sphere of health-keeping fitness; creation of tracking programmes for the perfection of theoretical and practical preparedness of fitness coaches.

\section{REFERENCES}

1. Butenko H., Goncharova N., Saienko V. \& Tolchieva H. Use of health tourism as a basis for improving physical condition of primary school age children. Journal of Physical Education and Sport. 2017. 17(1), Art. 6. P. 34-39.

2. Kononets N., Grynova M., Zhamardiy V., Mamon O. and Liulka H. Problems of Implementation of The System of Resource-Based Learning of Future Teachers of Physical Culture // International Journal of Applied Exercise Physiology. 2020.9 (12). P. 50-60.

3. Kononets N., Ilchenko O., Mokliak V. Future teachers resource-based learning system: experience of higher education institutions in Poltava city, Ukraine. Turkish Online Journal of Distance Education-TOJDE. July 2020. ISSN 1302-6488 Volume 21. Number 3. Article 14. P. 199_ 220.

4. Kornosenko O. K. \& Danysko O. V. Implementation of Step Training Simulator in the Process of Professional Training of Future Specialists in Physical Culture, [in:] Informational Technologies and Means of Education, National Academy of Pedagogical Sciences of Ukraine, Institute of 
Inform. Technologies and Means of Education, University of Educational Management ed. 2017. 58(2). P. 98-107.

5. Nash M. Let's work on your weaknesses': Australian CrossFit coaching, masculinity and neoliberal framings of 'health' and 'fitness'. Sport in Society. 2018. 21(9). P. 1432-1453.

6. Oluwajana D., IdowuA., Nat M., Vanduhe V. \& Fadiya S. The Adoption of Students' Hedonic Motivation System Model to Gamified Learning Environment. Journal of Theoretical and Applied Electronic Commerce Research. 2019. 14(3). P. 156-167.

7. Rapkiewicz J. A., NunesJ. P., Mayhew J. L., Franchini E. \& Amarante Do Nascimento M. Effects of Muay Thai training frequency on body composition and physical fitness in healthy untrained women. Journal of Sports Medicine and Physical Fitness. 2018. 58(12). P. 1808-1814.

8. Rustaden A. M., Gjestvang, C., Bø K., Hagen Haakstad L. A., \& Paulsen G. Body Pump versus traditional heavy load resistance training on changes in resting metabolic rate in overweight untrained women. Journal of Sports Medicine and Physical Fitness. 2017. 58(9). P. 1304-1311.

9. Shvedchykova I., Soloshych I., Kononets N., Grynova M. Creation of Electronic Educational Resources for Resource-Oriented Training of Electrical Engineering Students. IEEE Problems of Automated Electrodrive. Theory and Practice (PAEP). (21-25 Sept. 2020, Kremenchuk, Ukraine). P. $1-5$.

10. TolleH., Rapacz A., Weintraub B., Harkema S. J. \& Gibson J. L. Establishing the Neuro Recovery Network Community Fitness and Wellness facilities: multi-site fitness facilities provide activitybased interventions and assessments for evidence-based functional gains in neurologic disorders. Disability and Rehabilitation. 2018. 40(25). P. 3086-3093.

11. Vanchukhina L., Leybert T., Rogacheva A., Rudneva Y \& Khalikova E. New model of managerial education in technical university. International Journal of Educational Management. 2019. 33(3). P. 511-524.

12. Zhamardiy V. O., Donchenko V. I., Yemets A. V., Skrinnik Y. O. Physical Development by Means of Fitness Technologies as One of General Aspects of Student's Health / / Wiadomości Lekarskie. 2019. Tom LXXII, nr 5 cz II. P. 1074-1078.

13. Zhamardiy V., Griban G., Shkola O., Fomenko O., Khrystenko D., Dikhtiarenko Z., Yeromenko E., Lytvynenko A., Terentieva N., Otravenko O., Samokish I., Husarevych O. and Bloshchynskyi I. Methodical System of Using Fitness Technologies in Physical Education of Students // International Journal of Applied Exercise Physiology. 2020. 9 (5). P. 27-34.

14. Zhamardiy V., Shkola O., Tolchieva H., Saienko V. Fitness Technologies in the System of Physical Qualities Development by Young Students // Journal of Physical Education and Sport. 2020. Vol 20 (1), Art 19. pp. 142-149.

15. Zhamardiy V. O., Shkola O. M., Okhrimenko I. M., Strelchenko O. G., Aloshyna A. I., Opanasiuk F. H., Griban G. P., Yahodzinskyi V. P., Mozolev O. M., Prontenko K. V. Checking of the Methodical System Efficiency of Fitness Technologies Application in Students' Physical Education // Wiadomości Lekarskie. 2020. Tom LXXIII, nr 2. P. 332-341.

16. Zhamardiy V., Shkola O., Ulianova V., Bilostotska O., Okhrimenko I., Okhrimenko S., Griban G., Prontenko K., Bloshchynskyi I. Influence of Fitness Technologies on the Student Youth's Physical Qualities Development // Revista Dilemas Contemporáneos: Educación, Política y Valores. Año : VII, Número : Edición Especial, Artículo no. : 49. Período : Octubre, 2019.

17. Zhamardiy V., Shkola O., Bezpaliy S., Kalynovskyi B., Vasylenko O., Ivanochko I., Dovgan N., Malynskyi I., Danylenko O., Griban G., Prontenko K. Modern Fitness Technologies in the Physical Education of Students // Revista Dilemas Contemporáneos: Educación, Política y Valores. Año : VII, Número : Edición Especial, Artículo no. : 81. Período : Noviembre, 2019.

18. Zhamardiy V., Shkola O., Boichenko A., Prystynskyi V., Kornosenko O., Dmytrenko K., Kabatska O., Staroselska Y., Hordiienko O. and Postova S. Dynamics of Physical Fitness of Students during Powerlifting Classes // International Journal of Applied Exercise Physiology. 2020. 9 (9). P. 49-60.

19. Zhamardiy V., Shkola O., Otravenko O., Momot O., Andreieva M., Andrieieva O., Mudryk V., Slusarev V., Broslavska H. and Putiatina G. Dynamics of the Functional State of Students in the Process of Powerlifting in Higher Education // International Journal of Applied Exercise Physiology. 2020.9 (10). P. 24-35. 
20. Zhamardiy V., Shkola O., Saienko V. and Tolchieva H. Model of Pedagogical System for Teaching Students Motor Actions in Powerlifting // International Journal of Applied Exercise Physiology. 2020.9 (12). P. 76-85.

21. Zhurat Y., Davydyuc N. \& Oliynyk M. Psychological and Pedagogical Factors of Activating the Masters Students Cognitive Intereststothe Study of Foreign Languages. Revista Romaneasca Pentru Educatie Multidimensionala. 2019. 11(1). P. 312-324. 